\section{Lipopolysaccharid-bindendes Protein}

\author{
H. Renz ${ }^{1}$ und B. Gierten ${ }^{2}$ \\ ${ }^{1}$ Institute of Laboratory Medicine and Pathobiochemistry, \\ Molecular Diagnostics, Philipps University Marburg, \\ University Hospital Gießen and Marburg GmbH, Marburg, \\ Deutschland \\ ${ }^{2}$ Institut für Medizinische Diagnostik GmbH, Immunologie, \\ Bioscientia, Ingelheim, Deutschland
}

\section{Synonym(e) LBP}

Englischer Begriff lipopolysaccharid-binding protein

Definition $>$ Akute-Phase-Proteine

Struktur LBP gehört zu einer Familie von lipidbindenden Proteinen wie BPI (,,bacterial permeability-increasing protein“), CETP (,,cholesterol ester transfer protein“) u. a.

Molmasse $58 \mathrm{kDa}$.

Synthese - Verteilung - Abbau - Elimination LBP wird konstitutiv von Hepatozyten synthetisiert. Die Synthese wird nach Stimulation mit LPS deutlich gesteigert.

Funktion - Pathophysiologie LBP (LPS) bindet an den Lipid-A-Anteil von bakteriellen Lipopolysacchariden, die in der Zellwand gramnegativer Bakterien vorkommen und in weit geringeren Konzentrationen auch in der Zellwand grampositiver Bakterien nachweisbar sind.

Es katalysiert bereits in niedrigen Konzentrationen dessen Transfer zu CD14-Rezeptoren, die beispielsweise auf Monozyten und anderen immunkompetenten Zellen nachweisbar sind und einen Teil des membranständigen LBP-Rezeptors bilden. Ein zweiter Teil dieses Rezeptors wird vom Toll-likeRezeptor 2 (TLR-2) gebildet. Die LPS-aktivierten Zellen setzen proinflammatorische Zytokine wie z. B. Interleukin6 , Interleukin-1 oder $>$ Tumornekrosefaktor- $\alpha$ frei.

Zellen, die kein $>$ CD14 exprimieren, können durch Bindung eines Komplexes aus LPS, LBP und löslichem CD14 stimuliert werden.

Untersuchungsmaterial - Entnahmebedingungen Serum, Plasma (Heparin-, EDTA-).

Analytik Immunologischer Chemilumineszenzassay.

\section{Konventionelle Einheit $\mu \mathrm{g} / \mathrm{L}$.}

Referenzbereich - Erwachsene $<15 \mu \mathrm{g} / \mathrm{L}$.

Referenzbereich - Kinder s. Erwachsene.

Indikation Erhöhte Werte bei:

- Sepsis

- SIRS (,systemic inflammatory response syndrome“)

- Abdominelle Infektionen, Colitis ulcerosa

- Hämolytisch-urämisches Syndrom (HUS)

- Nach ACVB-Operation

Diagnostische Wertigkeit Bei gramnegativer Sepsis sind Werte zu erwarten, die innerhalb von 6-12 Stunden nach LPS-Exposition bis zum 30-Fachen der Norm ansteigen. Maximalwerte werden im Allgemeinen nach ca. 48 Stunden erreicht. Erste klinische Studien zeigen, dass deutlich erhöhte LBP-Werte bei Patienten mit gramnegativer Sepsis mit signifikant erhöhter Mortalität verbunden sind.

\section{Literatur}

Schumann RR et al (1990) Structure and function of lipopolysaccharide binding protein. Science 249:1429-1431 